\title{
TGF- $\beta$-induced miR10a/b expression promotes human glioma cell migration by targeting PTEN
}

\author{
SHIHAI LIU ${ }^{1}$, JUNFENG SUN ${ }^{2}$ and QING LAN ${ }^{1}$ \\ ${ }^{1}$ Department of Neurosurgery, The Second Affiliated Hospital of Soochow University, Suzhou, Jiangsu 215004; \\ ${ }^{2}$ Department of Surgical Oncology, Zhejiang University School of Medicine, Hangzhou, \\ Zhejiang 310003, P.R. China
}

Received June 6, 2013; Accepted September 23, 2013

DOI: $10.3892 / \mathrm{mmr} .2013 .1709$

\begin{abstract}
Human gliomas are associated with high rates of morbidity and mortality. In the brain, increased mRNA levels of transforming growth factor $\beta$ (TGF- $\beta$ ) correlate with the degree of malignancy of human gliomas. miR10a/10b expression has been demonstrated to be associated with TGF- $\beta$ expression in brain tumors, and it is reported that TGF- $\beta$ induces miR10 expression. Therefore, miR10a/10b expression may be induced by TGF- $\beta$ expression and may be involved in the TGF- $\beta$-induced migration of brain tumor cells. The present study examined the expression of TGF- $\beta$ and miR10a/10b in the tissues of 10 patients with brain tumors using quantitative PCR (qPCR), and the correlation between TGF- $\beta$ and miR10a or miR10b expression was analyzed. Additionally, U251 and SHG-44 cells were treated with TGF- $\beta$ and the expression of miR10a/10b was examined. Further, cell migration was analyzed following transfection of U251 cells with miR10a/10b and the association between miR10a/10b and phosphatase and tensin homolog deleted on chromosome 10 (PTEN) was investigated. U251 cells were transfected with miR10a/10b inhibitors and a PTEN expression plasmid prior to TGF- $\beta$ treatment and then cell migration was assessed. A significant correlation was identified between TGF- $\beta$ and miR10a expression ( $\mathrm{r} 2=0.6936, \mathrm{P}=0.007)$ and between TGF- $\beta$ and miR10b expression $(\mathrm{r} 2=0.5876, \mathrm{P}=0.02)$ in the tissues of patients with brain tumors. The results also showed that TGF- $\beta$ induces miR 10a/10b expression and that TGF- $\beta$-induced miR10a/10b expression promotes cell migration through the suppression of PTEN. In conclusion, TGF- $\beta$-induced miR10a/10b promotes brain tumor migration. This study may provide a number of suggestions for the clinical treatment of brain tumors.
\end{abstract}

Correspondence to: Professor Qing Lan, Department of Neurosurgery, The Second Affiliated Hospital of Soochow University, 1055 Sanxiang Road, Suzhou, Jiangsu 215004, P.R. China Email: lanqing_sz@126.com

Key words: miR10a/10b, TGF- $\beta$, cell migration, PTEN, brain tumor

\section{Introduction}

Human gliomas are one of the main types of malignancy in the central nervous system. Gliomas are the most aggressive form of brain tumor and are associated with high rates of morbidity and mortality (1). Despite the recent advances in surgery, radiotherapy and chemotherapy, the survival chances of patients with glioma remain poor. The median overall survival of patients with malignant glioma is $<1$ year and local recurrence occurs in $>90 \%$ of patients (2). As the survival rates of cancer patients improve, the incidence of brain metastases is rising (3). Transforming growth factor $\beta$ (TGF- $\beta$ ) promotes cancer metastases (4).

TGF- $\beta$ is a multifunctional cytokine involved in the regulation of cell proliferation, differentiation and survival or apoptosis of numerous types of cell. It induces epithelial mesenchymal transition (EMT) through the activation of downstream signaling pathways, including Smad and non-Smad signaling pathways. TGF- $\beta$ induces Akt activation through PI3K during EMT in various cell types. Once activated, Akt initiates the mTOR signaling pathway which is involved in cell survival, growth, migration and invasion (5). In the brain, TGF- $\beta$ is normally expressed at a very low level, which increases markedly following injury. Increased mRNA levels of the three TGF- $\beta$ isoforms (5) correlate with the degree of malignancy of human gliomas (6). Blocking the action of TGF- $\beta$ inhibits tumor viability, migration and metastases in mammary cancer, melanoma and prostate cancer models.

MicroRNAs (miRNAs), a class of small noncoding RNAs, are a novel type of gene expression regulator as they target mRNAs for translational repression or cleavage. Deregulation of miRNAs has been demonstrated in a variety of tumors, including breast cancer, leukemia, lung cancer and colon cancer, which indicates a significant correlation between miRNAs and human tumor malignancy (7). miRNAs are targets for anticancer therapies as their activity is efficiently blocked by sequence-specific oligonucleotides or other antisense approaches (8). miR10a and miR10b have been demonstrated to be upregulated in glioblastomas and anaplastic astrocytomas, reaching $>100$-fold overexpression in certain cases $(9,10)$. The miRNAs miR10a and miR10b are close homologs, differing by a single central nucleotide. In 
the mouse embryo, miR10a is mainly expressed in a region of the posterior trunk (11), whereas miR10a in adult mice is broadly expressed, with the highest levels identified in the kidney, muscle, lung and liver. The miR10a homolog miR10b is highly overexpressed in several tumor types and is reportedly involved in the progression of cancer (12).

miR10a regulates the metastatic properties of hepatocellular cancer (HCC) by directly targeting EphA4 (13) and is involved in the metastatic behavior of pancreatic cancer (14). The homolog of miR10a, miR10b, has been suggested to enhance the migration and invasion of metastatic breast cancer cells by repressing the translation of HoxD10 (15-17). In addition, it is reported that miR-10b is expressed in glioma tumors but not in normal brain cells, neural progenitor cells or mature glia or neurons (18-20). Therefore, miR10a/10b is considered a target for anti-glioma therapy (21).

The present study investigated whether miR10a/10b expression is associated with TGF- $\beta$ expression levels in brain tumor tissues. It has previously been reported that TGF- $\beta$ induces miR10a expression in Treg cells (22). Furthermore, the present study evaluated the hypothesis that the 3 ' untranslated region (3'UTR) of phosphatase and tensin homolog deleted on chromosome 10 (PTEN) contains binding sequences for miR10a and miR10b. Tumor suppressor PTEN is a dual-specific phosphatase that is a negative regulator of the PI3K-AKT-mTOR signaling pathway, thus controlling a variety of processes associated with cell survival, proliferation and growth (23). Therefore, the theory that miR10a and miR $10 b$ are induced by TGF- $\beta$ and involved in TGF- $\beta$-induced metastasis by suppressing PTEN expression in brain tumors was evaluated.

\section{Materials and methods}

Human tissue samples. Fresh, frozen human brain tumor samples were obtained from the Department of Neurosurgery at the Integrated Chinese and Western Medicine Hospital of Zhejiang Province (Hangzhou, China). The study protocol was approved by the institutional Ethics Committee of the Integrated Chinese and Western Medicine Hospital of Zhejiang Province and informed consent was obtained from all patients or patients' families.

Cell cultures and treatment. Human glioma U251 and SHG-44 cells were obtained from the Cell Bank of the Chinese Academy of Sciences (Shanghai, China). The U251 and SHG-44 cells were cultured in RPMI-1640 medium (Gibco-BRL, Carlsbad, CA, USA) supplemented with $10 \%$ fetal calf serum (PAA Laboratories $\mathrm{GmbH}$, Linz, Austria) at $37^{\circ} \mathrm{C}$ under $5 \%$ humidified $\mathrm{CO}_{2}$ and $100 \mu \mathrm{g} / \mathrm{ml}$ each of streptomycin and penicillin $\mathrm{G}$ was added (Amresco, Solon, OH, USA). Cells were treated with TGF- $\beta$ (5 ng/ $\mathrm{ml}$ ) and were transfected with miR10a and/or 10b mimics, miR10a and/or 10b inhibitors (Guangzhou RiboBio Co., Ltd., Guangzhou, China) or the PTEN expression plasmid pCDNA3.1-PTEN.

RNA isolation and quantitative PCR (qPCR). RNA was extracted using TRIzol (Invitrogen, Carlsbad, CA, USA). Total RNA $(1 \mu \mathrm{g})$ was reverse-transcribed using a RevertAid
First Strand cDNA Synthesis kit (Fermentas, Waltham, MA, USA). miR10a/10b, U6, TGF- $\beta$, PTEN and $\beta$-actin expression levels were measured using SYBR-Green (Roche, Mannheim, Germany). The expression of each target gene was determined by triplicates from three to six separate experiments and normalized using $\beta$-actin and miR10a/10b normalized using U6. qPCR Assays-on-Demand were performed using the ABI PRISM 7300 Sequence Detection system 2.1 (PE Applied Biosystems, Foster City, CA, USA) using relative quantification. Analysis and fold differences were determined using the comparative cycle threshold (CT) method. Fold change was calculated from the ${ }^{\Delta \Delta C T}$ values with the formula $2^{-\Delta \Delta C T}$.

Western blot analysis. Anti-PTEN and anti-GAPDH rabbit monoclonal antibodies were obtained from Cell Signaling Technology, Inc. (Danvers, MA, USA). Protein (100 $\mu \mathrm{g})$ was subjected to $12 \%$ SDS-PAGE and transferred onto polyvinylidene difluoride membranes (Millipore, Billerica, MA, USA). The membranes were blocked for $1 \mathrm{~h}$ in PBST $(10 \mathrm{mM}$ Tris- $\mathrm{HCl}, \mathrm{pH} 7.4,150 \mathrm{mM} \mathrm{NaCl}, 0.05 \%$ Tween-20) containing $2 \%$ nonfat dried milk. Subsequently, Anti PTEN $(1: 1,000)$ and anti GAPDH $(1: 1,000)$ rabbit monoclonal antibodies were incubated with the membranes. After $2 \mathrm{~h}$, the primary antibodies were washed and the mouse anti-rabbit secondary antibodies (Cell Signaling Technology) were incubated with the membranes. Protein bands were detected by an enhanced chemiluminescence reaction (ECL Detection; Millipore).

Migration assay. The migration assay was performed using 24-well transwell chambers ( $8 \mu \mathrm{m}$; Millipore). The U251 cells transfected with miR10a/10b mimics, miR10a/10b inhibitors or pCDNA3.1-PTEN were suspended in RPMI-1640 medium without serum and $2 \times 10^{4}$ cells were seeded onto Matrigel ${ }^{\mathrm{TM}}$ inserts in triplicate. They were then placed into a 24-well culture plate containing $500 \mu \mathrm{l}$ RPMI-1640 medium with or without $5 \mathrm{ng} / \mathrm{ml}$ TGF- $\beta$. Following culture for a total of $48 \mathrm{~h}$, cells on the upper side of the filters were removed with cotton-tipped swabs and the filters were washed with PBS. Cells on the underside of the filters were examined and counted under a microscope. Images were obtained with four randomly selected fields from each insert The number of cells in each field was counted and averaged. Migration is expressed as fold increase compared with the control.

Constructs for luciferase reporter assays. Primers were designed to the region of the PTEN 3'UTR believed to contain $\mathrm{miR} 10 \mathrm{a} / \mathrm{b}$ binding sequences using Primer Premier 5 (Premier Biosoft, Palo Alto, CA, USA). The primers were as follows: forward, AATGGCAATAGGACATTGTG and reverse, TACATGACACAGCTACACAA. The PTEN 3'UTR fragment was cloned from human genomic DNA into the pGL3-control-luciferase vector (Promega, Madison, WI, USA). Constructed plasmids were confirmed by sequencing.

Luciferase assays. Cells were plated in 24-well plates at a density of $1.5 \times 10^{4}$ cells per well. Each well received $250 \mathrm{ng}$ of a pGL3-pro-luciferase reporter and $5 \mathrm{ng}$ of a Renilla luciferase reporter (Promega). The cells were harvested using Passive Lysis buffer (Promega) following co-transfection 

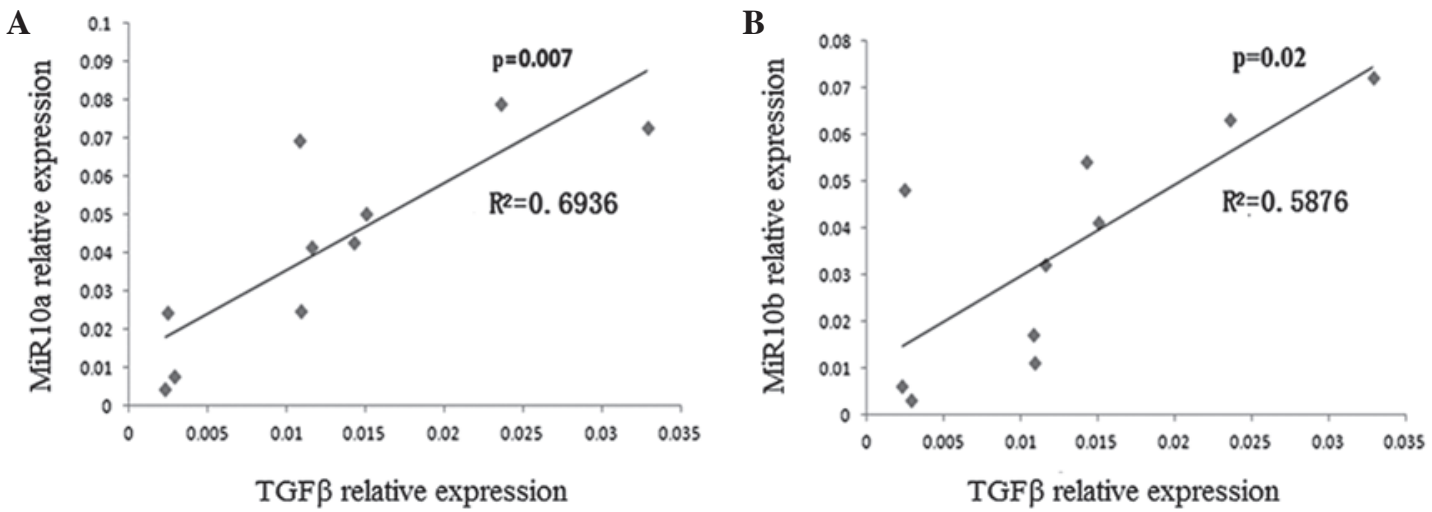

Figure 1. miR10a and 10b expression is associated with TGF- $\beta$ expression levels in the tumor tissues of glioma patients. (A) Spearman's correlation coefficient $[\mathrm{rs}]=\mathrm{r}^{2}=0.6936, \mathrm{P}=0.007$ (miR10a). (B) $\mathrm{r}^{2}=0.5876, \mathrm{P}=0.02$ (miR10b). TGF- $\beta$, transforming growth factor $\beta$.

A

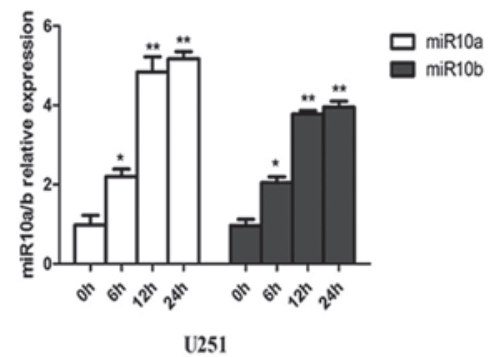

C

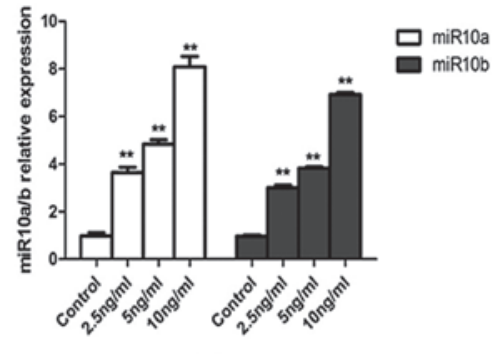

B

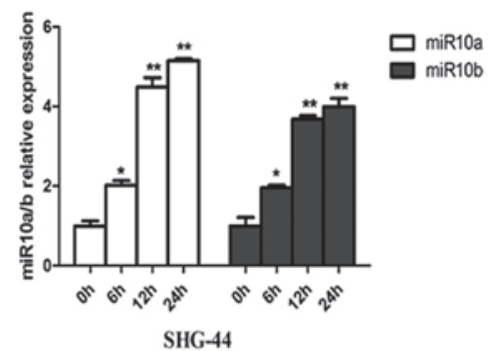

D

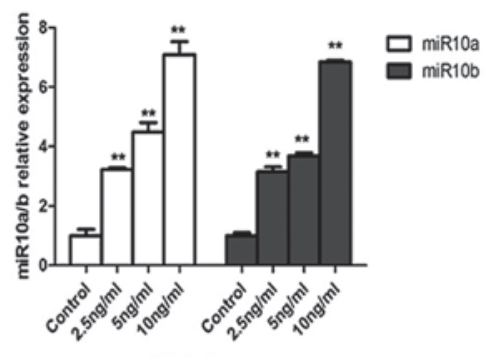

U251

SHG-44

Figure 2. TGF- $\beta$ induces the expression of miR10a and miR10b in U251 and SHG-44 cells. miR10a/10b expression was determined by qPCR as described in Materials and methods. (A) U251 cells and (B) SHG-44 cells were treated with $5 \mathrm{ng} / \mathrm{ml}$ TGF- $\beta$ for the time indicated and as described in Materials and methods; (C) U251 cells and (D) SHG-44 cells were treated with the different concentrations of TGF- $\beta$ as indicated. The results are shown as the mean \pm SE. from three representative independent experiments. ${ }^{*} \mathrm{P}<0.05,{ }^{* *} \mathrm{P}<0.01$ compared with the control. TGF- $\beta$, transforming growth factor beta.

with PTEN 3'UTR constructs and miR10a/10b or their inhibitor for $24 \mathrm{~h}$. Luciferase and Renilla luciferase activities were determined using a Dual-Luciferase Reporter assay system (Promega) in a Plate Chameleon luminometer (BioScan, Inc., Washington, DC, USA). Firefly luciferase was normalized by Renilla luciferase to correct for transfection efficiency. Fold induction was determined by dividing the averaged normalized values from each treatment by the control value for each transfection condition within that experiment. Values were averaged from multiple experiments, as indicated in the figure legends.

Statistical analysis. Statistical analyses were performed using GraphPad Prism 5.01 software, version (GraphPad Software, San Diego, CA, USA). Two-tailed Student's t-tests were used for the pair-wise comparison of experimental groups. Statistical significance was defined at the $\geq 95 \%$ confidence interval or $\mathrm{P} \leq 0.05$. In each figure, asterisks indicate significant differences from the controls $(\mathrm{P}<0.05)$. Bar graphs represent the mean \pm standard error of the mean of the number of independent experiments indicated in each figure legend. In addition, the analysis of the correlations among miR10a/10b, TGF- $\beta$ and PTEN expression in human glioma patients was conducted by bivariate analysis using Spearman's correlation coefficient.

\section{Results}

miR10a/10b expression is associated with TGF- $\beta$ expression levels in human glioma samples. The expression of TGF- $\beta$ and miR10a/10b was measured in the tissues of 10 patients with brain tumors using qPCR. The correlation between TGF- $\beta$ and miR10a or miR10b expression was analyzed according to the method described in Materials and methods. As shown in Fig. 1, there was a significant association between TGF- $\beta$ and miR10a expression $(\mathrm{r} 2=0.6936, \mathrm{P}=0.007)$ and between TGF- $\beta$ and miR10b expression $(\mathrm{r} 2=0.5876, \mathrm{P}=0.02)$ in the tissues of the patients with brain tumors. 
A

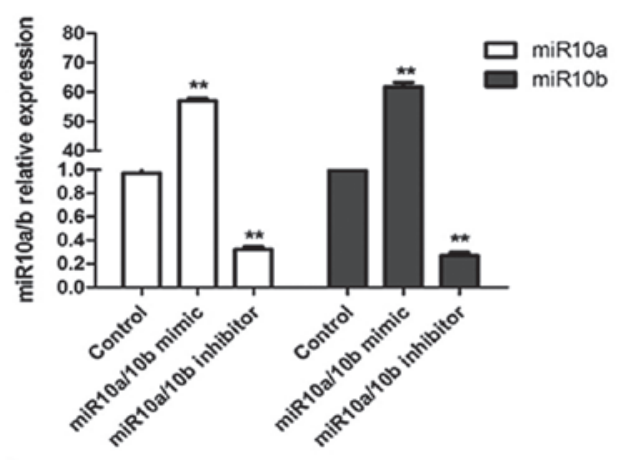

B

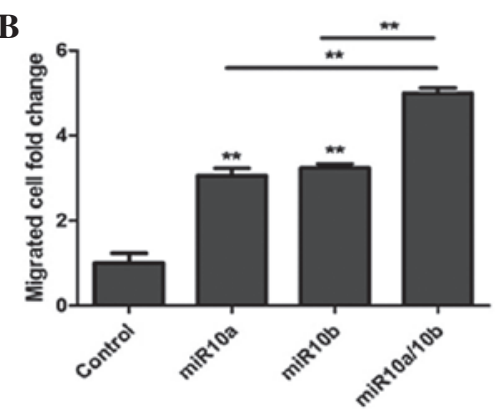

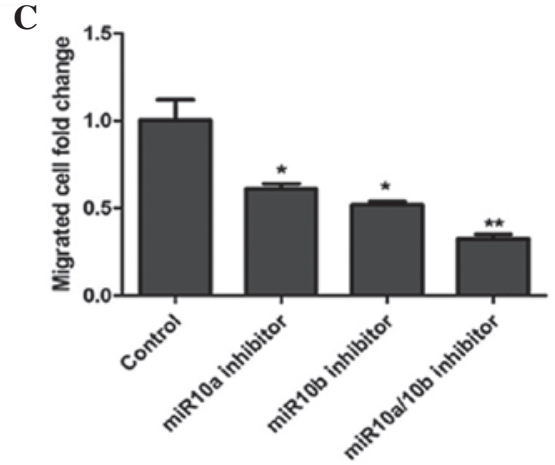

Figure 3. miR10a and miR10b promote human glioma cell migration. (A) miR10a/10b mimics and inhibitors were transfected into U251 cells for $24 \mathrm{~h}$, then miR10a and miR10b expression was confirmed by qPCR for transfection efficiency analysis. (B) miR10a and miR10b mimics and (C) miR10a and miR10b inhibitors were transfected or co-transfected into U251 cells for $48 \mathrm{~h}$. Cell migration was then assessed using a transwell assay. The results are shown as the mean \pm SE. from three representative independent experiments. ${ }^{*} \mathrm{P}<0.05,{ }^{* * *} \mathrm{P}<0.01$ compared with the control.

A

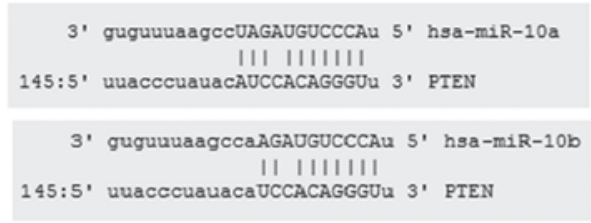

C

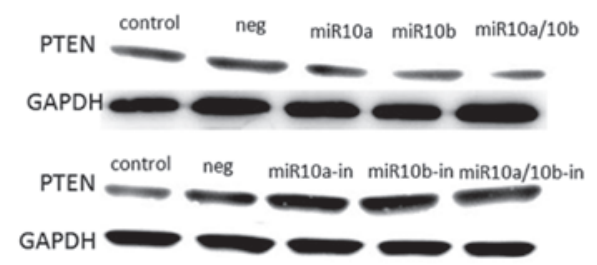

B

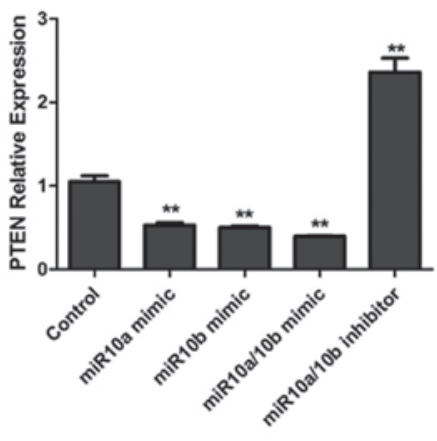

D

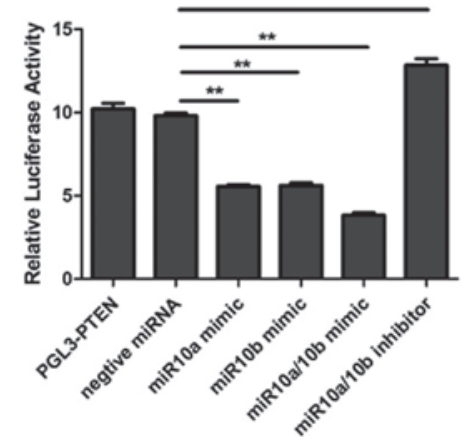

Figure 4. miR10a and 10b target PTEN. (A) The PTEN 3'UTR has binding sequences for miR10a and miR10b. (B) U251 cells were transfected with the indicated miRNAs for a total of $24 \mathrm{~h}$. PTEN expression was evaluated by qPCR. (B) U251 cells were transfected with the indicated miRNAs for a total of $48 \mathrm{~h}$. (C) Representative western blots of PTEN and GAPDH are shown. (D) The luciferase activity of U251 cells was measured following co-transfection with the indicated PTEN 3'UTR constructs and miR10a/10b or their inhibitor for $24 \mathrm{~h}$. The results are shown as the mean \pm SE. from three representative independent experiments. ${ }^{* *} \mathrm{P}<0.01$ vs control. PTEN, phosphatase and tensin homolog deleted on chromosome 10; 3'UTR, 3' untranslated region.

TGF- $\beta$ promotes migration and miR10a/10b expression in glioma cells. TGF- $\beta$ is believed to promote cell EMT and migration. As miR $10 \mathrm{a} / 10 \mathrm{~b}$ expression is associated with the expression levels of TGF- $\beta$ in brain tumor patients and it is reported that miR10a/b also promotes cell migration, further investigations were carried out to determine whether miR10a/10b is the direct target gene of TGF- $\beta$. U251 and SHG-44 cells were treated with TGF- $\beta$, and the levels of miR 10a/10b expression were measured by qPCR (Fig. 2). The miR10a and miR10b expression levels were significantly upregulated by TGF- $\beta$ in the two cell lines (Fig. 2A and $\mathrm{B})$. Concentration-response experiments demonstrated a maximal miR10a/10b induction with $10 \mathrm{ng} / \mathrm{ml}$ TGF- $\beta$ after $12 \mathrm{~h}$ of treatment in U251 and SHG-44 cells, which was 5-8 fold above that in the control groups (Fig. 2C and D).
Since $5 \mathrm{ng} / \mathrm{ml}$ TGF- $\beta$ is close to the physiological concentration (24), this concentration was used in the following experiments.

TGF- $\beta$-induced miR10a/10b expression strengthens glioma cell migration. To define the functional impact of TGF- $\beta$-induced miR $10 \mathrm{a} / 10 \mathrm{~b}$ expression, a migration assay was conducted as described in Materials and methods. miR10a and miR10b mimics were transfected into U251 cells and after $24 \mathrm{~h}$, miR10a and miR10b expression was evaluated by qPCR. As shown in Fig. 3A, the miR10a and miR $10 \mathrm{~b}$ mimics significantly increased the expression levels of miR10a/10b and their inhibitors significantly decreased the expression levels of miR10a/10b compared with the control levels. Following transfection with miR10a/10b 

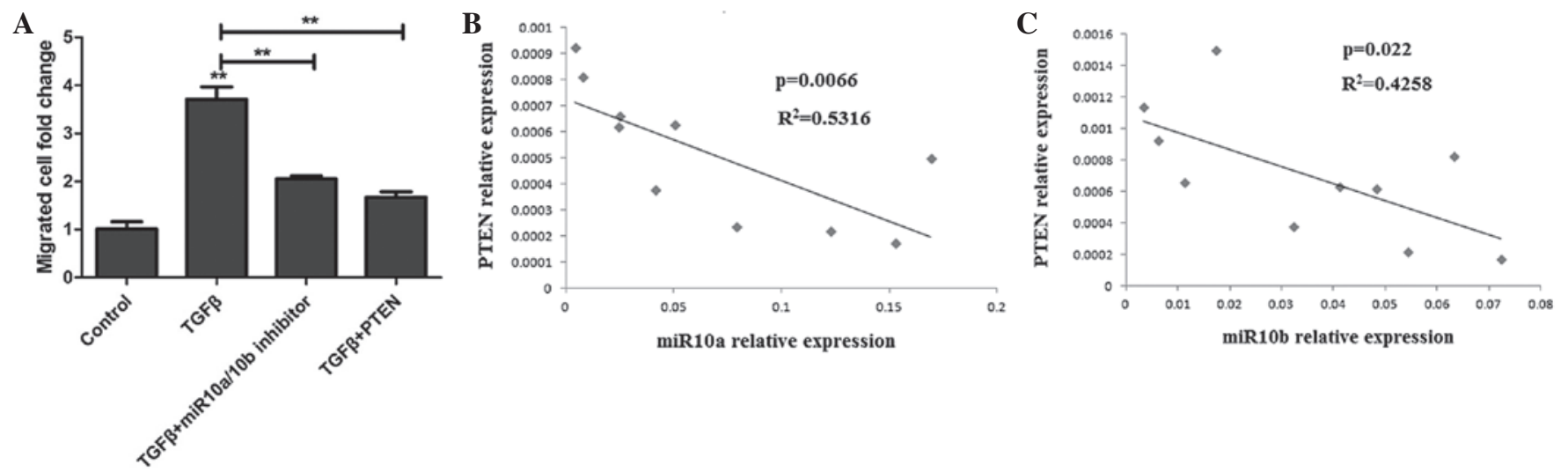

Figure 5. TGF- $\beta$-induced miR10a/10b promotes glioma cell migration through targeting PTEN. (A) Prior to TGF- $\beta$ treatment, U251 cells were transfected with $\mathrm{miR} 10 \mathrm{a} / 10 \mathrm{~b}$ inhibitors or a PTEN expression plasmid for a total of $48 \mathrm{~h}$. Subsequently, cell migration was analyzed. The results are shown as the mean \pm SE. from three representative independent experiments. Correlations of the expression levels of (B) miR10a and (C) miR10b with that of PTEN in brain tumor patients ${ }^{*} \mathrm{P}<0.05,{ }^{* *} \mathrm{P}<0.01$ vs control. TGF- $\beta$, transforming growth factor beta; PTEN, phosphatase and tensin homolog deleted on chromosome 10.

mimics or inhibitors, U251 cell migration was assessed. As shown in Fig. 3B, treatment of U251 cells with miR10a/10b mimics resulted in brain tumor cell migration. However, in cells pretreated with miR10a/10b inhibitor, cell migration was inhibited (Fig. 3C).

TGF- $\beta$-induced miR10a/10b expression promotes glioma cell migration through targeting PTEN. PTEN as a tumor suppressor inhibits cell proliferation and migration by blocking PI3K-AKT signaling. Through online software [miRanda (http://diana.cslab.ece.ntua.gr/microT/), TargetScan (http:// www.targetscan.org/) and PicTar (http://pictar.mdc-berlin. $\mathrm{de} /$ )], it was identified that the PTEN 3'UTR contains binding sequences for miR10a and miR10b(Fig.4A). To further establish that miR10a/10b targets PTEN, miR10a and miR10b mimics and inhibitors were transfected into U251 cells. The results demonstrated that miR10a and miR10b mimics downregulated PTEN expression levels and their inhibitors upregulated PTEN expression levels (Fig. 4B and C). Furthermore, the luciferase reporter analysis results identified that miR10a and miR10b mimics significantly suppressed the expression of a luciferase reporter gene fused to the 3'UTR region of PTEN, which was reversed by the further introduction of a miR $10 \mathrm{a} / 10 \mathrm{~b}$ inhibitor in U251 cells (Fig. 4D). These results confirmed that miR10a/10b suppresses PTEN expression through binding to its 3'UTR. To further investigate whether TGF- $\beta$-induced cell migration occurs through miR10a/10b targeting PTEN, U251 cells were transfected with miR10a/10b inhibitors or the pCDNA3.1-PTEN plasmid prior to TGF- $\beta$ treatment. After $48 \mathrm{~h}$, the migrated cells were analyzed and the results demonstrated that the miR10a/10b inhibitor inhibits TGF- $\beta$-induced cell migration and that the PTEN overexpression plasmid has a similar effect to the inhibitor (Fig. 5A). These results indicate that TGF- $\beta$-induced miR10a/10b expression inhibits PTEN expression, which results in brain tumor cell migration.

miR10a/lob expression positively correlates with PTENexpression in clinical human glioma patients. As TGF- $\beta$-induced miR10a and miR10b expression promotes cell migration via targeting PTEN, it was further investigated whether PTEN expression was associated with the miR10a/10b expression detected in the cells of human clinical glioma specimens. As shown in Fig. 5B and C, PTEN and miR10a/10b expression is correlated in brain tumor patients.

\section{Discussion}

Metastatic brain tumors are malignant neoplasms that spread to the brain from elsewhere in the body and represent the most common neurologic manifestation of cancer, occurring in up to $15 \%$ of cancer patients. Brain metastases are the most common type of intracranial tumor in adults, accounting for $\sim 40 \%$ of intracranial neoplasms (25). With the improving survival rates of cancer patients, the incidence of brain metastases has been rising (2).

TGF- $\beta$ elicits tumor-promoting effects through its ability to induce EMT, which enhances invasiveness and metastasis (26). TGF- $\beta$ induces EMT through the activation of downstream signaling pathways, including Smad and non-Smad signaling pathways. TGF- $\beta$ induces Akt activation through PI3K during EMT in various cell types. Once activated, Akt initiates the mTOR signaling pathway which is involved in cell survival, growth, migration and invasion (5).

It has been reported that TGF- $\beta$ promotes the expression of miR181b, miR192 and miR21 (27-29). In addition, Takahashi et al reported that TGF- $\beta$ induced the expression of miR10a in Treg cells (22). The present study demonstrated that TGF- $\beta$ promotes the expression of miR10a and miR10b.

The microRNAs miR10a and mi10b enhance cell migration. The homolog of miR10a, miR10b, has been suggested to enhance tumor cell migration and the invasion of metastatic breast cancer cells by repressing the translation of HoxD10 (16). In addition, miR10a is believed to regulate the metastatic properties of HCC by directly targeting EphA4 (13). miR-10b inhibits translation of the mRNA of HOXD10, a transcription factor known for its roles in cell motility, resulting in the increased expression of a pro-metastatic gene, RHOC. It also promotes the cell migration and invasion of human esophageal squamous cell carcinoma cells by the direct regulation of KLF4 (30). In addition, miR-10b targets neurofibromin 1 mRNA, leading to the activation of RAS signaling in neurofibromatosis type I (31). The overexpression of miR10b in 
non-metastatic cell lines has been demonstrated to promote tumor invasion and metastasis in a xenograft mouse model (21).

TGF- $\beta$-induced miR10a/10b targets PTEN. It has been reported that PTEN, an important tumor suppressor, is regulated by multiple miRNAs (32). It has also been demonstrated that miR21 increases tumor cell proliferation, migration and invasion through targeting PTEN (33). The present study indicated that miR10a and miR10b target PTEN.

In conclusion, the present study demonstrated that miR10a/10b expression is associated with TGF- $\beta$ expression in human glioma tissues and it further affirmed that TGF- $\beta$ induces the expression of miR $10 \mathrm{a} / 10 \mathrm{~b}$ in human glioma cells. Furthermore, it demonstrated that TGF- $\beta$-induced miR10a/10b expression promotes the migration of human glioma cells through targeting the tumor suppressor, PTEN. This study may provide a number of suggestions for human glioma clinical treatment.

\section{References}

1. Chan XH, Nama S, Gopal F, Rizk P, Ramasamy S, Sundaram G, et al: Targeting glioma stem cells by functional inhibition of a prosurvival oncomiR-138 in malignant gliomas. Cell Rep 2: 591-602, 2012.

2. Zhang X, Yang H, Gong B, Jiang C and Yang L: Combined gene expression and protein interaction analysis of dynamic modularity in glioma prognosis. J Neurooncol 107: 281-288, 2012.

3. Mathupala SP, Mittal S, Guthikonda M and Sloan AE: MicroRNA and brain tumors: a cause and a cure? DNA Cell Biol 26: 301-310, 2007.

4. Fu H, Hu ZL, Wen JF, Wang KS and Liu Y: TGF- $\beta$ promotes invasion and metastasis of gastric cancer cells by increasing fascin1 expression via ERK and JNK signal pathways. Acta Biochim Biophys Sin (Shanghai) 41: 648-656, 2009.

5. Kaminska B, Kocyk M and Kijewska M: TGF beta signaling and its role in glioma pathogenesis. Adv Exp Med Biol 986: 171-187, 2013.

6. Connolly EC, Freimuth J and Akhurst RJ: Complexities of TGF- $\beta$ targeted cancer therapy. Int J Biol Sci 8: 964-978, 2012.

7. Nicoloso MS and Calin GA: MicroRNA involvement in brain tumors: from bench to bedside. Brain Pathol 18: 122-129, 2008.

8. Hwang HW and Mendell JT: MicroRNAs in cell proliferation, cell death, and tumorigenesis. Br J Cancer 94: 776-780, 2006.

9. Gaur A, Jewell DA, Liang Y, Ridzon D, Moore JH, Chen C, Ambros VR and Israel MA: Characterization of microRNA expression levels and their biological correlates in human cancer cell lines. Cancer Res 67: 2456-2468, 2007.

10. Pang JC, Kwok WK, Chen Z and Ng HK: Oncogenic role of microRNAs in brain tumors. Acta Neuropathol 117: 599-611, 2009.

11. Mansfield JH, Harfe BD, Nissen R, Obenauer J, Srineel J, Chaudhuri A, et al: MicroRNA-responsive 'sensor' transgenes uncover Hox-like and other developmentally regulated patterns of vertebrate microRNA expression. Nat Genet 36: 1079-1083, 2004.

12. Garzon R, Pichiorri F, Palumbo T, Iuliano R, Cimmino A, Aqeilan R, et al: MicroRNA fingerprints during human megakaryocytopoiesis. Proc Natl Acad Sci USA 103: 5078-5083, 2006.

13. Yan Y, Luo YC, Wan HY, et al: MicroRNA-10a is involved in the metastatic process by regulating Eph tyrosine kinase receptor A4-mediated epithelial-mesenchymal transition and adhesion in hepatoma cells. Hepatology 57: 667-677, 2013.

14. Weiss FU, Marques IJ, Woltering JM, Vlecken DH, Aghdassi A, Partecke LI, et al: Retinoic acid receptor antagonists inhibit miR-10a expression and block metastatic behaviour of pancreatic cancer. Gastroenterology 137: 2136-2145, 2009.
15. Ørom UA, Nielsen FC and Lund AH: MicroRNA-10a binds the 5'UTR of ribosomal protein mRNAs and enhances their translation. Mol Cell 30: 460-471, 2008.

16. Ma L, Teruya-Feldstein J and Weinberg RA: Tumour invasion and metastasis initiated by microRNA-10b in breast cancer. Nature 449: 682-688, 2007.

17. Liu Z, Zhu J, Cao H, Ren H and Fang X: miR-10b promotes cell invasion through RhoC-AKT signaling pathway by targeting HOXD10 in gastric cancer. Int J Oncol 40: 1553-60, 2012.

18. Tian Y, Luo A, Cai Y, Su Q, Ding F, Chen H and Liu Z: MicroRNA-10b promotes migration and invasion through KLF4 in human esophageal cancer cell lines. J Biol Chem 285: 7986-7994, 2010

19. Sasayama T, Nishihara M, Kondoh T, Hosoda K and Kohmura E: MicroRNA-10b is overexpressed in malignant glioma and associated with tumor invasive factors, uPAR and RhoC. Int J Cancer 125: 1407-1413, 2009.

20. Garzon R, Garofalo M, Martelli MP, Briesewitz R, Wang L, Fernandez-Cymering C, et al: Distinctive microRNA signature of acute myeloid leukemia bearing cytoplasmic mutated nucleophosmin. Proc Natl Acad Sci USA 105: 3945-3950, 2008.

21. Lund AH: miR-10 in development and cancer. Cell Death Differ 17: 209-214, 2010.

22. Takahashi H, Kanno T, Nakayamada S, Hirahara K, Sciumè G, Muljo SA, et al: TGF- $\beta$ and retinoic acid induce the microRNA miR-10a, which targets Bcl-6 and constrains the plasticity of helper T cells. Nat Immunol 13: 587-595, 2012.

23. Luo H, Yang Y, Duan J, Wu P, Jiang Q and Xu C: PTEN-regulated $\mathrm{AKT} / \mathrm{FoxO} 3 \mathrm{a} / \mathrm{Bim}$ signaling contributes to reactive oxygen species-mediated apoptosis in selenite-treated colorectal cancer cells. Cell Death Dis 4: e481, 2013.

24. Wakefield LM, Letterio JJ, Chen T, Danielpour D, Allison RS, PaiLH, Denicoff AM, Noone MH, Cowan KH, O'Shaughnessy JA, et al: Transforming growth factor-betal circulates in normal human plasma and is unchanged in advanced metastatic breast cancer. Clin Cancer Res 1: 129-136, 1995.

25. Patel RR and Mehta MP: Targeted therapy for brain metastases: improving the therapeutic ratio. Clin Cancer Res 13: 1675-1683, 2007.

26. Heldin $\mathrm{CH}$, Vanlandewijck M and Moustakas A: Regulation of EMT by TGF- $\beta$ in cancer. FEBS Letters 586: 1959-1970, 2012.

27. Wang B, Hsu SH, Majumder S, Kutay H, Huang W, Jacob ST and Ghosal K: TGFbeta-mediated upregulation of hepatic miR-181b promotes hepatocarcinogenesis by targeting TIMP3. Oncogene 29: 1787-1797, 2010.

28. Chung AC, Huang XR, Meng X and Lan HY: miR-192 mediates TGF-beta/Smad3-driven renal fibrosis. J Am Soc Nephrol 21: 1317-1325, 2010.

29. Dey N, Ghosh-Choudhury N, Kasinath BS and Choudhury GG: TGF $\beta$-stimulated microRNA-21 utilizes PTEN to orchestrate AKT/mTORC1 signaling for mesangial cell hypertrophy and matrix expansion. PLoS One 7: e42316, 2012.

30. Tian Y, Luo A, Cai Y, Su Q, Ding F, Chen H and Liu Z: MicroRNA-10b promotes migration and invasion through KLF4 in human esophageal cancer cell lines. J Biol Chem 285: 7986-7994, 2010

31. Chai G, Liu N, Ma J, Li H, Oblinger JL, Prahalad AK, et al: MicroRNA-10b regulates tumorigenesis in neurofibromatosis type 1. Cancer Sci 101: 1997-2004, 2010.

32. Zhang BG, Li JF, Yu BQ, Zhu ZG, Liu BY and Yan M: microRNA-21 promotes tumor proliferation and invasion in gastric cancer by targeting PTEN. Oncol Rep 27: 1019-1026, 2012.

33. Meng F, Henson R, Wehbe-Janek H, Ghoshal K, Jacob ST and Patel T: MicroRNA-21 regulates expression of the PTEN tumor suppressor gene in human hepatocellular cancer. Gastroenterology 133: 647-658, 2007. 